\title{
Linkage and mutation analysis in an extended family with Charcot-Marie-Tooth disease type 1B
}

Eva Nelis, Vincent Timmerman, Peter De Jonghe, Ludo Muylle, Jean-Jacques Martin, Christine Van Broeckhoven

\begin{abstract}
Charcot-Marie-Tooth disease type 1 (CMT1) or hereditary motor and sensory neuropathy type I (HMSNI) is an autosomal dominant peripheral neuropathy. In most families the disease segregates with a $1.5 \mathrm{Mb}$ duplication on chromosome 17p11.2 (CMT1A). A few patients have been found with point mutations in the PMP-22 gene. In some families linkage has been found with markers located on chromosome 1q21-q25 (CMT1B) and more recently mutations have been identified in the $\mathbf{P}_{0}$ gene.

We analysed an extended CMT1 pedigree (CMT-B) without the CMT1A duplication. Significant positive linkage with chromosome 1 indicated that this family is of the CMT1B subtype. Sequencing of the candidate gene $P_{0}$ located in chromosome band 1q21-q23 showed a $C$ to $A$ point mutation at position 446 in exon 3 resulting in an Asp134Glu substitution. Since the $P_{0}$ mutation cosegregated with CMT1 disease we suggest that this mutation is the primary genetic cause of CMT1B in family CMT-B.
\end{abstract}

(f Med Genet 1994;31:811-815)

Laboratory of Neurogenetics, Born Bunge Foundation (BBS), University of Antwerp, Belgium Antwerp

V Timmerman

P De Jonghe

C Van Broeckhoven

Division of

Haematology,

Academic Hospital

(UZA), Antwerp,

Belgium

L Muylle

\section{Laboratory of} Neuropathology, Born

Bunge Foundation

(BBS), Department of

Medicine, University

of Antwerp (UIA),

Belgium

J-J Martin

Correspondence to

Dr Van Broeckhoven,

Neurogenetics Laboratory,

Born Bunge Foundation,

University of Antwerp (UIA)

University of Antwerp (UIA),

Universiteitsplein 1, B-2610

Antwerpen, Belgium.

Received 7 April 1994

Revised version accepted for publication 25 May 1994

The hereditary motor and sensory neuropathies (HMSN) include clinically and genetically heterogeneous disorders of the peripheral nervous system. ${ }^{1}$ The prevalence of all HMSN forms is estimated as 1 in $10000 .^{2}$ HMSN type I or Charcot-Marie-Tooth disease type 1 (CMT1) is the most common form, characterised by progressive atrophy and paresis of distal limb muscles, depressed or absent deep tendon reflexes, and pes cavus deformity. The disease is mostly inherited as an autosomal dominant trait. The major electrophysiological and neuropathological features of CMT1 are nerve conduction velocities (NCV) of the median motor nerve below $38 \mathrm{~m} / \mathrm{s}$, and segmental de- and remyelination with onion bulb formations on peripheral nerve biopsy.

In the majority of CMT1 families designated CMT1A, the disease cosegregates with a 1.5 $\mathrm{Mb}$ duplication on chromosome $17 \mathrm{p} 11.2^{3-5}$ comprising the peripheral myelin protein 22 (PMP-22) gene. ${ }^{5} \mathrm{~A}$ few CMT1A patients have a single base mutation in the PMP-22 gene, proving that PMP-22 is involved in CMT1 pathogenesis. $^{5-7}$
A minor CMT1B locus has been located on chromosome 1q, close to the Duffy blood group (FY) locus and the Fc $\gamma$ RII gene. ${ }^{89}$ The major peripheral myelin protein $\mathrm{P}_{0}$ gene has been mapped to mouse chromosome 1 , in a region syntenic to human chromosome 1q21-q23. ${ }^{10}$ Mutations of the $P_{0}$ gene have been observed recently in CMT1 patients identifying the $P_{0}$ gene as the CMT1B gene. ${ }^{511-13}$

\section{Methods}

MARKER ANALYSIS

Restriction fragment length polymorphisms (RFLPs) were recognised by the following chromosome 17p11.2 DNA markers: pEW301 (D17S58), pA10-41 (D17S71), pVAW409R3a (D17S122), pVAW409R1b (D17S122), pVAW412R3HEc (D17S125), pEW401 (D17S61), pEW503 (D17S67), and pVAW410R1 (D17S123). The chromosome 1q21-q23 DNA markers used were $3021 \mathrm{E} 1$ (SPTA), PUM24P (PUM), 16.2pCD (FCG2), and pAG2 (AT3). The restriction fragment length polymorphisms (RFLPs) are described in detail in Genome Data Base (GDB). All manipulations, including isolation of genomic and plasmid DNA, digestion with restriction enzymes, Southern blot transfer of genomic DNA, and hybridisation with radiolabelled plasmid DNA were done according to standard procedures.

Primers flanking the CA repeat poly-

\section{LINKAGE ANALYSIS}

Two and multipoint lod scores were calculated respectively with the programs MLINK and LINKMAP of the LINKAGE computer package, version $5 \cdot 1 .{ }^{15}$ Complete penetrance, autosomal dominant inheritance, and a gene frequency of 0.0001 was defined for the CMT1 phenotype. Equal male and female recombination rates were assumed. Multipoint recombination distances between the markers were obtained from Wright et $a l^{16}$ for chromosome 17 and Lebo et $a l^{9}$ for chromosome 1. Allele frequencies for the markers FCG2 and RM11-GT were obtained from seven married in persons from the CMT-B family. In- 
formation on allele and haplotype frequencies for all other markers were obtained from GDB.

\section{MUTATION ANALYSIS}

Manual and automated sequencing was performed. Part of the coding region of the $P_{0}$ gene was amplified by standard PCR using primers based on exon sequences. Two primer sets were used: one for amplification of the sequence between exons 2 and 3 (length of PCR fragment: $550 \mathrm{bp}$ ), that is, $\mathrm{P}_{0} \operatorname{ex} 2 \mathrm{~F}$ (5'-GGCCATCGTGGTTTACACCG-3')/ $\mathbf{P}^{-}$ ex3R (5'-GGTTGTCCCTTGGCATAGTG$\left.3^{\prime}\right)$ and one for amplification of the sequence between exons 3 and 6 (length of PCR fragment: $1000 \mathrm{bp})$, that is, $P_{0} \operatorname{ex} 3 \mathrm{~F}\left(5^{\prime}-\right.$ CCACTATGCCAAGGGACAAC- $\left.3^{\prime}\right) / \mathbf{P}_{0}$ ex6R (5'-CCTTGGCCTTCTTCTCACTG-3'). For sequencing we used the same primers or internal primers of exon $4\left(\mathrm{P}_{0} \operatorname{ex} 4 \mathrm{R} 5^{\prime}\right.$ CTGAGCCTCCTCTGCAGG-3' ${ }^{\prime}$ ) and exon 5 ( $\mathbf{P}_{0}$ ex5F 5'-GGGAAATTGCACAAGCCAGG-3'; $P_{0}$ ex5R 5'-GCTTCGACGCGTCCTTTCCT-3'). Intronic primers were used to complete the sequencing of exon 3 ( $\mathrm{P}_{0}$ ex3P4 5'-TCATTAGGGTCCTCTCACATGC3'; $P_{0}$ ex3-M21 5'-GCCTGAATAAAGGTCCTTAG-GC-3'), exon 5 ( $\mathbf{P}_{0}$ ex5-P6 5'-GAAGAGGAAGCTGTGTCCGC-3'; $\mathrm{P}_{0} \mathrm{ex5-M5}$ 5'-CACATCAGTCACCGAGCGCGACT-3'), and exon 6 (P $\mathrm{P}_{0}$ ex6-P41 5'-AGTCGCTCGGTGACTGAT-3'; $\mathrm{P}_{0}$ ex6-M46 5'-TAGCTCCATCTCGATGACCA-3'). For manual sequencing we used a biotinylated primer in the PCR amplification and the PCR product was bound to streptavidin coated magnetic beads. After denaturation the single stranded DNA was sequenced using the dideoxy method. For automated sequencing we used the Prism Sequenase Terminator Double Stranded Sequencing Kit (Applied Biosystems). Electrophoresis and analysis was performed on a 373A DNA sequencer (Applied Biosystems).

Single strand conformational polymorphism (SSCP) analysis was performed by amplification of exon 3 of $\mathrm{P}_{0}$ using the intronic primer set $\mathrm{P}_{0}$ ex3-P4/ $\mathrm{P}_{0}$ ex3-M21. Standard polymerase chain reactions were carried out in the presence of $\left[\alpha-{ }^{32} P\right] d C T P$. Samples were subjected to electrophoresis on a $1 \times$ HydroLink MDE (J T Baker) gel at $45 \mathrm{~W}$ for 330 minutes at $4^{\circ} \mathrm{C}$.

\section{Results}

FAMILY CMT-B

Since the finding of the $1.5 \mathrm{Mb}$ duplication in CMT1A patients we have tested a large number of CMT1 families for the presence of the CMT1A duplication using Southern blot hybridisation of $M s p I$ digested DNA with probes pVAW409R3a, pVAW412HEb, and pEW $401 \mathrm{HE}^{17}$ and of $F s p$ I digested DNA with probe pVAW409R3a. ${ }^{18}$ In $14(82.5 \%)$ out of 17 CMT1 families the CMT1A duplication was present. ${ }^{1719}$ In all CMT1 families analysed, the clinical picture of the patients was consistent with a CMT1 phenotype according to the diagnostic criteria agreed upon by the European CMT consortium group, ${ }^{20}$ that is, patients had slowly progressive symmetrical muscle atrophy and weakness, severely decreased motor nerve conduction velocity (median NCV $<30 \mathrm{~m} / \mathrm{s}$ ), and absence or marked decrease of sensory nerve action potentials in the lower limbs. In only one of the three non-duplicated CMT1 families (family CMT-B) was the pedigree size sufficient for linkage analysis studies. The pedigree of family CMT-B consisted of five generations comprising 75 persons of whom 18 were clinically affected. The pattern of inheritance of the disease was autosomal dominant. Most patients had NCVs measured in the motor median nerve giving a mean value of $13.1 \mathrm{~m} / \mathrm{s}(\mathrm{SD} 3 \cdot 3)$. The proband had a sensory nerve biopsy consistent with a diagnosis of demyelinating neuropathy. Blood samples for DNA analysis were obtained from 29 family members of family CMT-B (fig 1). All patients and at risk persons in generations III to $\mathrm{V}$ had a neurological examination. Most patients had an electrophysiological examination to confirm their disease status while only one asymptomatic at risk person (IV.17) had NCVs measured that were normal.

\section{LINKAGE ANALYSIS}

Linkage analysis was performed in family CMT-B using RFLP and CA repeat markers located on chromosomes 17p11.2-p12 and 1q22-q25. Two point lod scores were calculated for the disease and are shown in the table. Recombinants were observed with the chromosome 17 markers D17S58, D17S71, and D17S123 located outside the CMT1A region as well as with D17S122 located inside the CMT1A duplication. Positive but nonsignificant lod scores were obtained with D17S122, D17S125, and D17S61, all located in the CMT1A duplication. In contrast, most of the chromosome 1 markers gave positive lod scores in the absence of recombinants. Conclusive two point lod scores were reached with the markers FCG2 and APOA2 suggesting that family CMT-B is a CMT1B family.

This was essentially confirmed by the multipoint linkage analyses of chromosomes $17 \mathrm{p} 11.2$ and 1q22-q25 markers. The multipoint lod scores obtained with the markers D17S58, D17S122, and D17S123 exclude linkage of the disease in family CMT-B to the CMT1A region with an exclusion distance of $17.5 \mathrm{cM}$ spanning the CMT1A duplication. The multipoint lod scores obtained with the markers SPTA, FY, FCG2, and AT3 confirm linkage of the disease in family CMT-B to the CMT1B region with a maximum lod score of $4 \cdot 85$ at the FCG2 locus.

\section{SEQUENCE ANALYSIS OF $P_{0}$ IN CMT-B}

Since it was shown that the major peripheral myelin protein $\mathrm{P}_{0}$ gene is located on mouse chromosome 1 in a region syntenic to the region of human chromosome 1 comprising the CMT1B region, we decided to perform a sequence analysis of this gene in patients of 
I

III
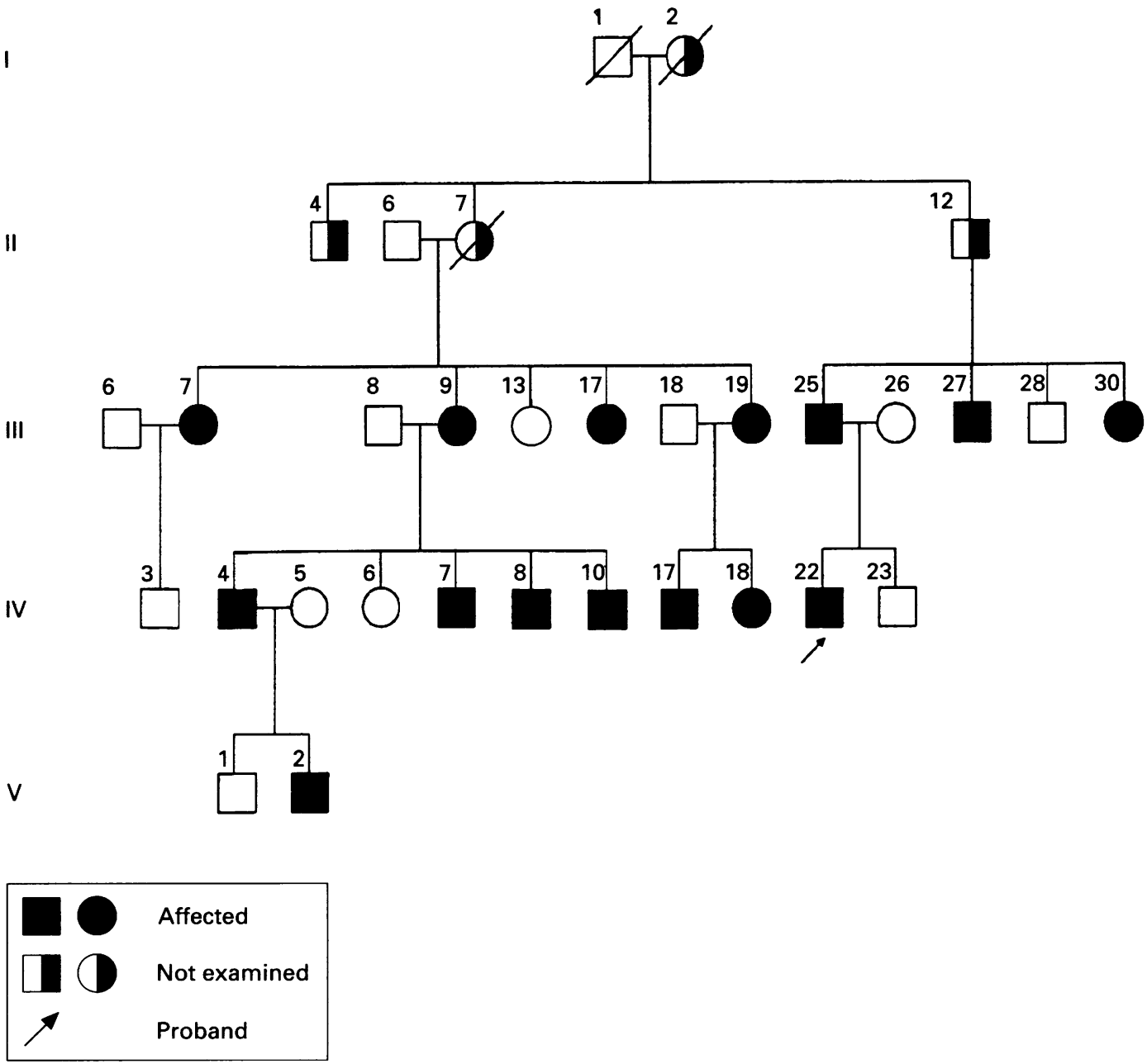

Figure 1 Linkage pedigree of family CMT-B affected with autosomal dominant CMT1.

Pedigree numbers refer to the position of the persons in the complete pedigree.

family CMT-B. Unfortunately no frozen nerve biopsy material of the proband was available. Also, at that moment only the human cDNA sequence of $P_{0}$ was known. ${ }^{21}$ Therefore, we had to use genomic DNA for direct PCR sequencing using primers designed on the basis of the cDNA sequence of the human $\mathrm{P}_{0}$ gene. In rat and mouse the genomic organisation of the $P_{0}$ gene was known, showing the intron/ exon boundaries of six exons coding for $P_{0}$. Using this information we deduced the location of the exonic sequences in the human CDNA sequence of $P_{0}$ assuming that human $P_{0}$ is also coded for by six exons. Two primer sets were designed based on the sequence of exons 2 and 3 and exons 3 and 6 respectively to amplify the genomic DNA of two affected and two unaffected subjects from family CMT-B. Subsequently the sequence of exons 2 to 6 was determined using either the primers used in the PCR amplification or internal primers designed based on the sequence of exons 4 and 5. Also, intronic sequence information obtained during the sequencing analysis was used to design additional primers. We were able to determine the complete coding sequence of exons 3, 4, 5 , and 6 as well as the sequence of introns 3 , 4 , and 5 (the nucleotide sequence data will appear in the EMBL, GenBank, and DDBJ Nucleotide Sequence Databases under the accession numbers U10017 and U10018). The location of the intron/exon boundaries is in good agreement with that in the rat and mouse genomic sequences. In the patients' DNA a C to A base change in exon 3 at position 446 was observed (fig $2 \mathrm{~A}$ ), resulting in an amino acid substitution at codon 134 changing an Asp to a Glu (codon numbering according to Hayasaka $e t a l .{ }^{21}$ ) The patients were heterozygous for the Asp134Glu mutation showing both the normal and the mutant allele. Compared to the published human cDNA sequence, ${ }^{21}$ a silent homozygous mutation of $\mathrm{G}$ to $\mathrm{A}$ was also detected in exon 2 at codon 72 coding for Gly.

SEGREGATION ANALYSIS OF $P_{0}$ IN CMT-B

Next we examined the segregation of the exon 3 mutation in family CMT-B. Since the mutation did not alter a restriction recognition site, we analysed segregation using SSCP analysis. All 15 patients showed an altered mobility of the exon 3 PCR fragments (fig 2B). Two at risk subjects in generation II who had no neurological or electrophysiological examination also had the altered SSCP pattern indicating that they are carrying the mutation. Subject II.4 was affected according to family informants. The two other subjects (II.7 and II.12) are obligatory carriers of the disease. None of the at risk persons who were clinically unaffected based on their neurological ex- 
A

$3^{\prime}$

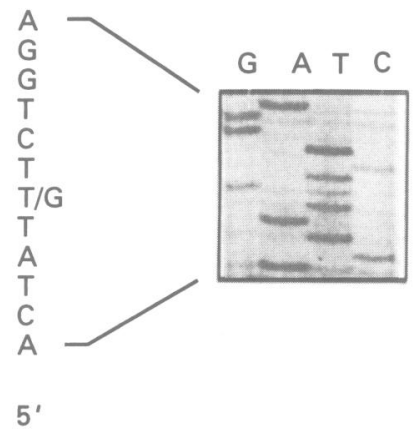

B

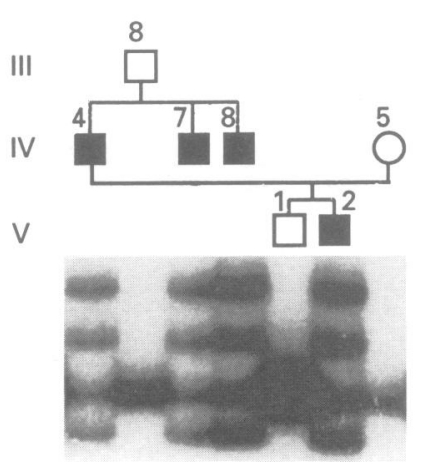

Figure 2 Mutation analysis in CMT-B. (A) Identification of the $C$ to $A$ mutation at position 446 of the $P_{0}$ gene in $C M T-B$ (sense strand). The presence of the mutation was confirmed by sequence analysis of the antisense strand (data not shown). Nucleotide numbering is according to Hayasaka et al. ${ }^{21}$ (B) SSCP analysis of the $P_{0}$ Asp134Glu mutation in family CMT-B (lower band). Segregation is shown for a part of the pedigree.

Two point lod scores in family CMT-B between CMT1 and markers of chromosome 17p11.2-p12 and $1 q 21-q 25$

\begin{tabular}{|c|c|c|c|c|c|c|c|}
\hline \multirow[t]{2}{*}{ Locus } & \multicolumn{7}{|c|}{ Recombination fraction $(\theta)$} \\
\hline & 0.00 & 0.01 & 0.05 & $0 \cdot 10$ & $0 \cdot 20$ & $0 \cdot 30$ & 0.40 \\
\hline $\begin{array}{l}\text { Chromosome } 17 \\
\text { D17S58 } \\
\text { D17S71 } \\
\text { D17S122* } \\
\text { D17S122† } \\
\text { D17S125 } \\
\text { D17S61 } \\
\text { D17S123 } \\
\text { D17S67 }\end{array}$ & $\begin{array}{l}-\infty \\
-\infty \\
-\infty \\
-\infty \\
0 \cdot 33 \\
0 \cdot 04 \\
-\infty \\
0.23\end{array}$ & $\begin{array}{r}-0.73 \\
-1.91 \\
-0.45 \\
-0.65 \\
0.33 \\
0.04 \\
-2.68 \\
0.22\end{array}$ & $\begin{array}{r}0.49 \\
-1.04 \\
0.78 \\
0.80 \\
0.31 \\
0.03 \\
-1.34 \\
0.19\end{array}$ & $\begin{array}{r}0 \cdot 85 \\
-0.62 \\
1 \cdot 16 \\
1.26 \\
0 \cdot 28 \\
0.03 \\
-0.80 \\
0.15\end{array}$ & $\begin{array}{r}0.95 \\
-0.22 \\
1.25 \\
1.38 \\
0.22 \\
0.02 \\
-0.35 \\
0.08\end{array}$ & $\begin{array}{r}0.75 \\
-0.04 \\
1.02 \\
1 \cdot 10 \\
0 \cdot 15 \\
0.01 \\
-0.15 \\
0.04\end{array}$ & $\begin{array}{r}0.41 \\
0.02 \\
0.60 \\
0.62 \\
0.08 \\
0.00 \\
-0.05 \\
0.01\end{array}$ \\
\hline $\begin{array}{l}\text { Chromosome } 1 \\
\text { SPTA } \\
\text { FY } \\
\text { PUM } \\
\text { FCG2 } \\
\text { CRPt } \\
\text { APOA2† } \\
\text { AT3 } \\
\text { P } \neq\end{array}$ & $\begin{array}{l}0.99 \\
1.52 \\
-\infty \\
3.60 \\
1.00 \\
3.89 \\
0.23 \\
6.02\end{array}$ & $\begin{array}{r}0.97 \\
1.49 \\
-4.05 \\
3.54 \\
0.98 \\
3.82 \\
0.71 \\
5.92\end{array}$ & $\begin{array}{r}0.91 \\
1.37 \\
-0.84 \\
3.27 \\
0.92 \\
3.26 \\
0.66 \\
5.53\end{array}$ & $\begin{array}{l}0 \cdot 82 \\
1 \cdot 22 \\
0 \cdot 29 \\
2 \cdot 93 \\
0 \cdot 83 \\
3 \cdot 16 \\
0 \cdot 59 \\
5 \cdot 02\end{array}$ & $\begin{array}{l}0.65 \\
0.90 \\
0.98 \\
2.21 \\
0.65 \\
2.38 \\
0.46 \\
3.91\end{array}$ & $\begin{array}{l}0.45 \\
0.56 \\
0.93 \\
1.45 \\
0.46 \\
1.56 \\
0.32 \\
2.69\end{array}$ & $\begin{array}{l}0.24 \\
0 \cdot 21 \\
0.51 \\
0 \cdot 67 \\
0 \cdot 24 \\
0 \cdot 73 \\
0 \cdot 16 \\
1.31\end{array}$ \\
\hline
\end{tabular}

* Haplotyping of markers pVAW409R1 and pVAW409R3. †CA repeat. ¥Asp134Glu mutation.

amination but had no electrophysiological data showed the altered SSCP pattern. Two point lod scores were calculated between the $\mathrm{P}_{0}$ mutation and CMT1 disease and gave a maximum lod score of 6.02 at zero recombination (table). To assess whether the mutation represented a polymorphic sequence variation in the $\mathrm{P}_{0}$ gene present in the normal population, we analysed genomic DNA of 30 unrelated control subjects for the mutation by SSCP analysis of exon 3 . None of these persons showed altered mobilities of the PCR fragments indicating that the exon 3 mutation was not present.

\section{Discussion}

We performed linkage and mutation analyses in an extended CMT1 pedigree, CMT-B, in which the disease segregates according to an autosomal dominant pattern. No CMT1A duplication was observed with markers for the CMT1A region. The negative lod scores with DNA markers in the $17 \mathrm{p} 11.2$ region excluded the CMT1A locus as the disease region in family CMT-B. These findings were confirmed by the fact that a mutation analysis of the PMP22 gene was negative in family CMT-B (data not shown). With the chromosome 1q21-q25 markers, conclusive lod scores were obtained indicating that family CMT-B is of the CMT1B subtype.

The major structural peripheral myelin protein zero, $P_{0}$, is localised in the $1 \mathrm{q} 21-\mathrm{q} 23$ region and is a candidate gene for CMT1B. We established the sequence of the $\mathrm{P}_{0}$ gene by direct PCR sequencing in genomic DNA of patients and unaffected subjects of family CMT-B. In exon 3, a $\mathrm{C}$ to $\mathrm{A}$ mutation was detected at position 446 leading to an amino acid substitution of Asp by Glu at codon 134. The Asp134 codon is conserved among many species, such as mouse, rat, and bovine. SSCP analysis showed that all affected subjects of the family were mutated, while the married in and clinically unaffected at risk persons were not mutated. Also, the mutation was not present in 30 unrelated controls. These findings suggest that CMT1B disease in this family is caused by the amino acid substitution Asp 134Glu within the extracellular domain of $\mathbf{P}_{0}$.

A silent homozygous mutation observed in exon 2 of all affected and unaffected CMT-B family members was observed, indicating no relationship with the disease. The same mutation was also found by others and thus most likely represents a non-pathological polymorphism.

Five distinct single base mutations in $P_{0}$ resulting in an amino acid substitution have been identified in CMT1 patients using genomic DNA sequencing: Arg98His, Tyr82Cys, Lys96Glu, Asp90Glu, and Ile30Met. ${ }^{51113}$ In one CMT1B family cDNA sequencing identified a $3 \mathrm{bp}$ deletion present in all affected persons, resulting in a Ser deletion at codon 63. ${ }^{12}$ All these $\mathrm{P}_{0}$ mutations as well as the Asp134Glu mutation identified in this study are located in exons 2 or 3 , coding for the extracellular domain of $\mathbf{P}_{0}$. The extracellular domain consists of a variable-like immunoglobulin (Ig) domain. This domain has been hypothesised to play a role in the compaction of myelin by homophilic interaction. It is not yet known how the $P_{0}$ mutations influence the $P_{0}$ functioning. It is possible that the mutations affect the homophilic interaction and therefore disturb myelin formation. Another possibility is that the mutated $P_{0}$ protein is not properly inserted in the Schwann cell membrane, and that when remaining intracellular it is metabolically toxic.

CMT type 1 is a genetically heterogeneous disorder. Besides a common duplication on chromosome $17 \mathrm{p} 11.2$, a few point mutations in the PMP-22 gene, located in the CMT1A 
region, have been described. On chromosome 1 , seven different mutations in the $P_{0}$ gene have been found in CMT1 patients so far. Thus, CMT1 patients who are not duplicated for the CMT1A region should be screened for mutations in the $P_{0}$ as well as in the PMP22 gene to establish DNA diagnosis. CMT1 patients without CMT1A duplication or mutations in $\mathrm{P}_{0}$ or PMP-22 should be tested for mutations in other candidate genes for peripheral neuropathies. Recently, the gene coding for the gap junction protein connexin 32 (Cx32) located on chromosome Xq13.1 has been identified as the site of mutations in dominant $\mathrm{X}$ linked CMT1 families (CMTX). Therefore, in CMT1 patients in whom X linkage cannot be excluded, mutations in the $\mathrm{C} \times 32$ gene can also be sought.

The authors are grateful to all family members who cooperated in the research work. The authors would also like to thank
$G$ De Winter and G Smeyers for their help in contacting and informing the family and J De Voecht for technical assistance. This work was funded in part by a grant from the National Fund for Scientific Research (NFSR), the Concerted Action of the Flemish Ministry of Education, the Flemish Biotechnology the Flemish Ministry of Education, the Flemish Biotechnology Program of the Ministry of Economy, and Innogenetics Inc,
Gent, Belgium. VT is a research assistant and CVB is a research associated of the NFSR, Belgium.

1 Dyck PJ, Chance P, Lebo R, Carney JA. Hereditary motor and sensory neuropathies. In: Dyck PJ, Thomas PK, Griffin JW, Low PA, Poduslo JF, eds. Peripheral neuropathy. Grd ed. Philadelphia: Saunders, 1993:1094-136.

2 Emery AEH. Population frequencies of inherited neuromuscular diseases - a world survey. Neuromusc Dis 1991; muscular

3 Lupski JR, Montes de Oca-Luna R, Slaugenhaupt S, et al. DNA duplication associated with Charcot-Marie-Tooth DNA duplication associated with Chat

4 Raeymaekers P, Timmerman V, Nelis E, et al. CharcotMarie-Tooth neuropathy type la (CMT1a) is most likely caused by a duplication in chromosome 17p11.2. Neuromusc Dis 1991;1:93-7.

5 Patel PI, Lupski JR. Charcot-Marie-Tooth disease: a new paradigm for the mechanism of inherited disease. Trends Genet 1994;10:128-33.
6 Valentijn LJ, Baas F, Wolterman RA, et al. Identical point mutations of PMP-22 in Trembler-J mouse and CharcotMarie-Tooth disease type 1A. Nature Genet 1992;2:28891.

7 Nelis E, Timmerman V, De Jonghe $P$, Van Broeckhoven C. Identification of a $5^{\prime}$ splice site mutation in the PMP-22 Identification of a 5 splice site mutation in the PMP-22 gene in autosomal dominant Charcot-Marie-1

8 Bird TD, Ott J, Giblett ER. Evidence for linkage of CharcotMarie-Tooth neuropathy to the Duffy locus on chromosome 1. Am ₹ Hum Genet 1982;34:388-94.

9 Lebo RV, Chance PF, Dyck PJ, et al. Chromosome $1 \mathrm{Ch}$ arcot-Marie-Tooth disease (CMT1B) locus in the Fcr receptor gene region. Hum Genet 1991;88:1-12.

10 Oakey RJ, Watson ML, Seldin M. Construction of a physical map of mouse and human chromosome 1: comparison of $13 \mathrm{Mb}$ of mouse and $11 \mathrm{Mb}$ of human DNA. Hum Molec Genet 1992;1:613-20.

11 Hayasaka $\mathrm{K}$, Himoro $\mathrm{M}$, Sato $\mathrm{W}$, et al. Charcot-MarieTooth neuropathy type $1 B$ is associated with mutations of the myelin $P_{0}$ gene. Nature Genet 1993;5:31-4.

12 Kulkens T, Bolhuis PA, Wolterman RA, et al. Deletion of the serine 34 codon from the major peripheral myelin protein $\mathrm{P}_{0}$ gene in Charcot-Marie-Tooth disease type 1B. Nature Genet 1993;5:35-9.

13 Hayasaka K, Takada G, Ionasescu V. Mutation of the myelin $P_{0}$ gene in Charcot-Marie-Tooth neuropathy type $1 \mathrm{~B}$. Hum Molec Genet 1993;2:1369-72.

14 Hum Molec Genet 1993;2:1369-72. Backhovens $H$, et al. The Duffy blood group is linked to the $\alpha$-spectrin locus in a large pedigree with autosomal dominant inheritance of Charcot-Marie-Tooth type 1. Hum Genet 1988;78:76-8. 15 Lathrop GM, Lalouel JM. Easy calculations of lod scores and genetic risk on small computers. Am $\mathcal{F}$ Hum Genet 1984;36:460-5.

16 Wright EC, Goldgar DE, Fain PR, Barker DF, Skolninck MH. A genetic map of human chromosome 17p. Genomics 1990;7:103-9.

17 Raeymaekers P, Timmerman V, Nelis E, et al. Estimation of the size of the chromosome $17 \mathrm{p} 11.2$ duplication in
Charcot-Marie-Tooth neuropathy type 1a (CMT 1a). $\mathcal{f}$ Med Genet 1992;29:5-11.

18 Timmerman V, Nelis E, Van Hul W, et al. The peripheral myelin protein gene PMP-22 is contained within the Charcot-Marie-Tooth disease type 1A duplication. Nature Genet 1992;1:171-5.

19 Nelis E, Timmerman V, Raeymaekers $P$, De Jonghe $P$, Martin J, Van Broeckhoven C. Heterogeneity in CharcotMarie-Tooth type 1 (CMT 1) disease: evidence for a CMT 1 gene on chromosome 1. Eur $\mathfrak{f}$ Neurosci 1992; cMT 1 gene on

20 De Visser M. Diagnostic criteria for autosomal dominant hereditary motor and sensory neuropathy type 1a. Neuromusc Dis 1993;3:77-9.

21 Hayasaka $K$, Nanao $K$, Tahara $M$, et al. Isolation and sequence determination of $\mathrm{CDNA}$ encoding the major structural protein of human peripheral myelin. Biochem Biophys Res Commun 1991;180:515-8. 